EXTENDED REPORT

\title{
ICF based comparison of disease specific instruments measuring physical functional ability in ankylosing spondylitis
}

\author{
T Sigl, A Cieza, D van der Heijde, G Stucki
}

See end of article for authors' affiliations

\section{Correspondence to:} Professor Gerold Stucki, Department of Physical Medicine and Rehabilitation, LudwigMaximilians-University of Munich, Marchioninistr 15, 81377 Munich Germany; Gerold.Stucki@ med.uni-muenchen.de

Accepted 14 April 2005 Published Online First 20 April 2005
Objectives: To link validated and widely used instruments measuring physical functional ability in ankylosing spondylitis to the International Classification of Functioning, Disability, and Health (ICF) and to compare their contents, based on the results of the linking process.

Methods: The Bath Ankylosing Spondylitis Functional Index (BASFI), the Dougados Functional Index (DFI), the Health Assessment Questionnaire modified for the spondylarthropathies (HAQ-S), and the Revised Leeds Disability Questionnaire (RLDQ) were linked to the ICF separately by two trained health professionals according to 10 linkage rules.

Results: All concepts contained in the items of the selected instruments could be successfully linked to the ICF except for "illness" included in the HAQ-S. Altogether 55 different ICF categories were linked. Seven belonged to "body functions", 43 to "activities and participation", and five to "environmental factors". The component "body structure" was not contained in any of the four instruments. Only two ICF categories were common to all selected questionnaires, but there was a high level of concordance on the concepts represented in them. However, especially in terms of "activities and participation", the emphasised aspects differed.

Conclusions: The ICF provides an excellent common framework for the comparison of disease specific instruments for ankylosing spondylitis. For a future revision of the ICF, a specification of major limitations in patients with ankylosing spondylitis is suggested.
A nkylosing spondylitis is thought to be the most common and typical form of spondylarthropathy. Pain and spinal stiffness, often gradually leading to severe impairment in physical functioning and quality of life, are regarded as the most important complaints and therapeutic challenges in this disease. ${ }^{1-3}$

In 1998, during the OMERACT (Outcome Measures in Rheumatology Clinical Trials) conference, the members of the ASAS (Assessment in Ankylosing Spondylitis) working group selected "core sets" of outcome instruments to be applied in different kinds of trials in ankylosing spondylitis. ${ }^{4}$

Three core sets for three different settings were proposed. In all these core sets the ASAS recommended the obligatory use of the domains physical function, pain, spinal mobility, spinal stiffness, and patient global assessment. ${ }^{5}$

Physical functional ability is assessed using self administered instruments. The Bath Ankylosing Functional Index (BASFI), ${ }^{6}$ the Dougados Functional Index (DFI), ${ }^{78}$ the Health Assessment Questionnaire modified for the spondylarthropathies (HAQ-S), ${ }^{9}$ and the Revised Leeds Disability Questionnaire (RLDQ) ${ }^{10}$ are among the most widely used, well established, and internationally recommended instruments for measuring physical functional ability in ankylosing spondylitis. ${ }^{11-13}$ However, all these instruments have both strengths and weaknesses.

When selecting or comparing instruments for measuring physical functional ability in a research or clinical setting, accuracy, feasibility, and discrimination need to be considered. ${ }^{14}$ However, because of the different spectrum of items covered by the instruments a comparison between them is difficult.

The newly available International Classification of Functioning, Disability, and Health (ICF, formerly ICIDH$2)^{15}$ offers a possible solution to this dilemma. The ICF belongs to the family of classifications produced by the World Health Organisation and represents a comprehensive common framework for describing functioning and health. Using established linkage rules, ${ }^{16}$ items included in physical functional ability measures can be linked to the best corresponding ICF categories. Accordingly, our objectives in this study were to link the BASFI, the DFI, the HAQ-S, and the RLDQ to the ICF classification and to compare the contents of these four instruments

\section{METHODS \\ Measures \\ BASFI}

The BASFI is a self administered, disease specific instrument for ankylosing spondylitis, designed by a multiprofessional expert team of rheumatologists, physiotherapists, and research associates with a major input from patients. The final version, first published in 1994, consists of 10 questions altogether. Eight items concern activities referring to the functional anatomy of the patients, and two additional questions assess the patients' ability to cope with everyday life. ${ }^{6}$

\section{DFI}

The DFI is a self administered, disease specific instrument for ankylosing spondylitis designed by rheumatologists with special interest in ankylosing spondylitis and originally applied as an interview. The revised self administered

Abbreviations: ASAS, Assessment in Ankylosing Spondylitis working group; BASFI, Bath Ankylosing Spondylitis Functional Index; DFI, Dougados Functional Index; HAQ-S, Health Assessment Questionnaire modified for the spondylarthropathies; ICF, International Classification of Functioning, Disability and Health; RLDQ, Revised Leeds Disability Questionnaire 


\begin{tabular}{|c|c|c|}
\hline & $\begin{array}{l}\text { Estimated } \kappa \\
\text { coefficient }\end{array}$ & 95\% Bootstrapped CI \\
\hline Component & 0.78 & $(0.65$ to 0.91$)$ \\
\hline First level & 0.98 & $(0.95$ to 1.00$)$ \\
\hline Second level & 0.97 & $(0.91$ to 1.00$)$ \\
\hline Third level & 0.98 & $(0.98$ to 1.00$)$ \\
\hline
\end{tabular}

questionnaire contains 20 items corresponding to activities of daily living. ${ }^{78}$

\section{HAQ-S}

The HAQ-S is a self administered, disease specific instrument for ankylosing spondylitis. It was built on the standard HAQ designed for rheumatoid arthritis by adding five questions relating to neck and back functioning. Those were identified in a 1985 mailed survey of 300 British patients with ankylosing spondylitis (Peer K, Loughborough University, Nottingham, UK, personal communication, 1985). The HAQS consists of 25 items. $^{9}$

\section{RLDQ}

The RLDQ is a self administered, disease specific instrument for ankylosing spondylitis. During the revision process of the questionnaire a group of 12 patients with ankylosing spondylitis was interviewed, all of whom were attending a three week inpatient rehabilitation course. The RLDQ includes 16 items grouped into four areas: "mobility", "bending down", "reaching up and neck mobility", and "posture". ${ }^{10}$

ICF

The $\mathrm{ICF}^{15}$ was designed to record and organise a wide range of information about health and health related states in a standardised common language. The ICF consists of two major parts, each containing two separate components.

Part 1 covers Functioning and Disability and includes the following components: body functions (b), body structure (s), and activities and participation (d).

Part 2 covers Contextual factors and includes environmental factors (e), and personal factors (which have not yet been classified and are therefore not taken into account in this linkage study).

In the ICF classification, the letters b, s, d, and e-which refer to the components of the classification-are followed by a numerical code starting with the chapter number (one digit), followed by the second level (two digits), and the third and fourth levels (one digit each). The component letter with the suffix of two, three, or four digits corresponds to the code of the so called categories. Categories are the units of the ICF classification. Within each chapter, there are individual two, three, or four level categories. An example selected from the component "body functions" is as follows:

- b2 Sensory functions and pain (chapter level or first level)

- b280 Sensation of pain (second level)

- b2801 Pain in body part (third level)

- b28013 Pain in back (fourth level).

Within each component, the categories are arranged in a stem/branch/leaf scheme. Consequently, a lower level category shares the attributes of the higher level categories to which it belongs - that is, the use of a lower level (more detailed level) category automatically implies that the higher level category is applicable but not the other way round.
At the end of each embedded set of third or fourth level categories, as well as at the end of each chapter, there are "other specified" categories (uniquely identified by the final code 8 ). These categories allow the coding of aspects not included in any other specific categories. ${ }^{15}$

\section{Linkage of items to the ICF}

Tables showing the linkage process for the BASFI, the DFI, the HAQ-S, and the RLDQ can be requested from the corresponding author. All four selected instruments were linked to the ICF separately by two trained health professionals according to 10 linking rules. ${ }^{16}$ The linking rules are guidelines which enable concepts contained in health status measures to be linked to the ICF in a standardised manner. According to these rules, experts trained in the ICF are advised to link concepts contained in a health status measure to the ICF category representing this concept most precisely. The most important linking rules are summarised below.

If one item encompasses different concepts, the information in each concept should be linked. For example, in item 1 of the BASFI "Putting on your socks or tights without help or aids (e.g., sock aids)" the concepts "putting on your socks or tights", "help", and "aids (e.g., sock aids)" have been linked to the ICF separately (see table 1).

If the content of an item is not explicitly included in the corresponding ICF category - that is, the questionnaire provides more detailed information- "the other specified" option at the third or fourth coding level of the classification has to be applied. ${ }^{16}$ This can be illustrated by the fourth item of the DFI (" 4 , Can you get into a bathtub?") which was assigned to "d498"that is, "mobility, other specified." The additional information has to be documented as well as the selected ICF code.

If the content of an item is more general than the corresponding ICF category, the code of the higher level is linked. This can be illustrated by " 5 a, Getting up off the floor without help from lying on your back" of the BASFI which has been linked to the chapter "e3" of the classification ("support and relationships", defined as "(...) people or animals that provide physical or emotional support, nurturing, protection, assistance and relationships to other persons, in their home, place of work, school or at play or in other aspects of their daily activities". ${ }^{15}$

The abbreviation he is used for concepts concerning a health condition-for example, the concept "illness" included in the HAQ-S ("How much stiffness have you had because of your illness in the past week?").

To decide which ICF category should be linked to each item in the four questionnaires, consensus between the two health professionals was required. In case of disagreement concerning the selected categories a third independent assessor with expertise in the concept and taxonomy of the ICF and the linking rules was consulted to make a final decision on the most suitable code.

The percentage of cases in which the third independent assessor was consulted for a final decision on the most precise ICF category was calculated. In addition, the degree of agreement between the two health professionals concerning the component, first, second, and third ICF levels was calculated by means of the $\kappa$ statistic ${ }^{17}$ and the corresponding bootstrapped confidence intervals. ${ }^{18}$

The data analysis was carried out using SAS for Windows, version 8 .

\section{RESULTS}

\section{Linkage process}

All the 124 concepts contained in the items of the BASFI, DFI, HAQ-S, and RLDQ could be successfully linked to the ICF, except for "illness" contained in the HAQ-S. 
Table 2 Items of the Dougados functional index (DFI), the Bath ankylosing spondylitis functional index (BASFI), the revised Leeds disability questionnaire (RLDQ), and the health assessment questionnaire modified for the spondylarthropathies (HAQ-S) with the corresponding international classification of functioning, disability and health (ICF) categories

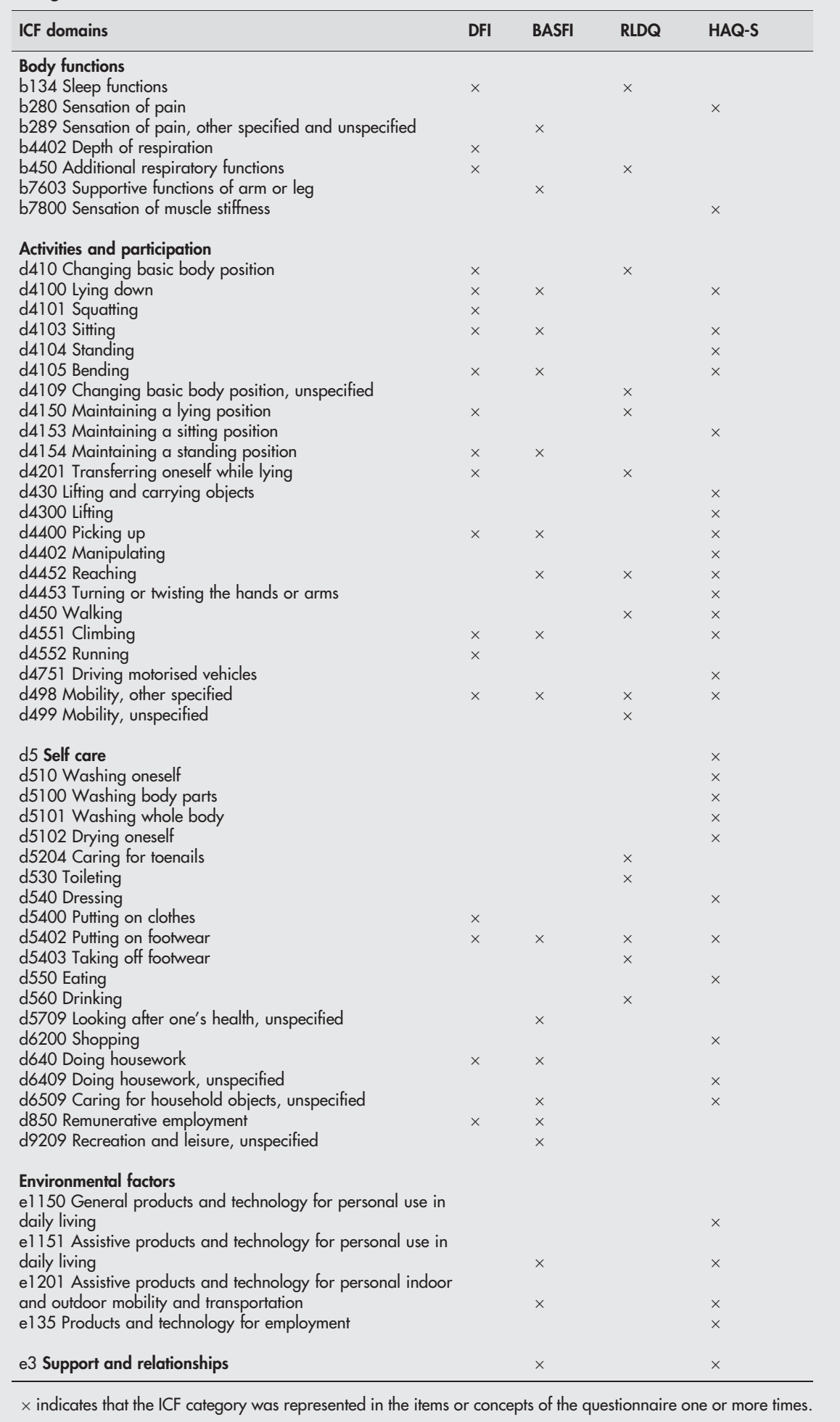

The third independent assessor was consulted for 26 of the 124 concepts $(21.0 \%)$. The results of the $\kappa$ statistic, as well as the bootstrapped confidence intervals for the component, first, second, and third ICF levels are presented in table 1 . The estimated $\kappa$ coefficients ranged from 0.78 at the component
ICF level to 0.98 at the first and third ICF level, respectively. The width of the $95 \%$ bootstrapped confidence interval, which indicates the precision of the estimated $\kappa$ coefficient was narrowest at the third level and widest at the component ICF level. 
Altogether 55 different ICF categories were linked. Seven belonged to the component "body functions", 43 to "activities and participation", and five to "environmental factors". The component "body structure" was not contained in any of the four selected instruments.

Throughout the linkage process we identified two ICF categories common to all four questionnaires.

\section{Linkage results}

The results of the linking process of the four selected instruments are presented in table 2 .

All questionnaires covered the ICF components "body function" and "activities and participation", whereas "environmental factors" were only represented in the BASFI and the HAQ-S.

Among the instruments selected, the HAQ-S was the one that could be linked to the most ICF categories (20) that were not contained in the others. Sixteen of these refer to "activities and participation", two to "body functions", and two to "environmental factors". Further specific analyses of the structure and the contents of the questionnaires during the linking process showed that the DFI represented more items relating to "body functions" (3) than the other selected instruments.

As revealed by the linking process, the questionnaires showed a high level of concordance in terms of the domains of functioning and health they covered, though each includes different aspects. This applied especially to the component "activities and participation" of the classification.

All four instruments focus on the chapter "d4" (mobility), reflected in 23 different ICF categories, though each of these includes specific concepts.

The DFI and the BASFI covers items that could be linked to the category "d410" (changing basic body position) and "d415" (maintaining a body position), whereas the HAQ-S focuses on mobility of the upper extremity, as shown by the concepts "lifting and carrying objects" (d430), "manipulating" (d4402), and "turning and twisting the hands or arms" (d4453). The DFI, BASFI, and HAQ-S include "picking up" (d4400), whereas the BASFI, RLDQ, and HAQ-S include "reaching" (d4452). The DFI, BASFI, and HAQ-S could be linked to "d455l" (climbing), while one item of the RLDQ was assigned to "mobility, unspecified" (d499).

The ICF concept "d5 self care" is represented in all four instruments. Items from each of them could be linked to the category "putting on footwear" (d5402). However, apart from this common aspect their different emphases are clearly separated. Items of the HAQ-S could be related to eight different ICF codes referring to d5 "self care", with the chapter as a whole or the aspects "washing oneself" (d510) and "eating" (d550) included. The latter two are not incorporated in the other three instruments selected.

The RLDQ could be linked to four ICF categories referring to "self care" which are not applicable for the other measures. These are "toileting" (d530), "caring for toenails" (d5204), "taking off footwear" (d5403), and "drinking" (d560).

The DFI covers "putting on clothes" (d5400), while the BASFI could be linked to "looking after one's health, unspecified" (d5709).

The BASFI and the DFI both incorporate "remunerative employment" (d850), whereas the BASFI and the HAQ-S cover "caring for household objects, unspecified" (d6509). The RLDQ could not be linked to aspects relating to "work and employment".

"Recreation and leisure, unspecified" (d6209) is only represented in the BASFI.

The BASFI covers three ICF categories and the HAQ-S covers five ICF categories relating to environmental factors.
Three of these are identical ("el151 assistive products and technology for personal use in daily living", "el201 assistive products and technology for personal indoor and outdoor mobility and transportation", and "e3 support and relationships").

Additionally, the HAQ-S includes one item that could be linked to the e-component at a more general and comprehensive level than the BASFI (el35 products and technology for employment) as well as one further item linkable to the third level category "general products and technology for personal use in daily living" (el150).

\section{DISCUSSION}

The ICF is very useful when comparing the contents of disease specific instruments for ankylosing spondylitis. Linkage to this classification of all the concepts included in the most commonly used self administered questionnaires for ankylosing spondylitis except "illness" (HAQ-S) has been possible, based on acknowledged linking rules. ${ }^{16}$

The degree of agreement between the two health professionals who carried out the linking procedure was high according to the $\kappa$ coefficient. However, estimation of the reliability of the linking process could be strengthened by increasing the number of raters in future studies.

By linking all four questionnaires to the ICF it could be shown that the classification is a very precise tool with few exceptions. This underscores the findings of Weigl et al. ${ }^{19}$

The precision of the ICF can be illustrated by, for example, items "19, to cough or sneeze" of the DFI and "coughing and sneezing" of the RLDQ, which can be transferred one to one to the ICF code "additional respiratory function" (b450) as they are included exactly in its definition.

The linking procedure showed that the DFI contains more items relating to "body functions" than the other three selected questionnaires. A possible explanation may be that the DFI was designed only by physicians ${ }^{78}$ as opposed to the other three selected measures which involved a major input from patients (HAQ-S, RLDQ) or from a multiprofessional team including physiotherapists and patients (BASFI). ${ }^{6}$

The linking process also showed that only the HAQ-S included "stiffness", and none of the selected instruments represented "pain in the back", which are regarded as some of the clinically most relevant features in patients with ankylosing spondylitis. ${ }^{2}$ This may be because the selected instruments were explicitly designed to assess patients' perception of their activities of daily living and not disease activity..$^{6-8} 12$

During the linking procedure another striking difference between the selected instruments measuring physical functional ability in ankylosing spondylitis becomes obvious. Whereas the BASFI and the HAQ-S include items and concepts referring to "environmental factors" of the classification, like "handrail or walking aid" (e1151 "assistive products and technology for personal use in daily living"), none of them is represented in the DFI and the RLDQ. A possible explanation for this could be the fusion of the expertise of a multiprofessional team and the experience of patients with ankylosing spondylitis in the questions of the BASFI and HAQ-S, respectively.

The e-component is not represented in the RLDQ. This may be because patients' advice was incorporated later on during the revision process of the questionnaire and was not included in its first drafts. ${ }^{10}$

Although the linking procedure revealed a high level of concordance in the ICF concepts represented in the four selected measures, especially those concerning "activities and participation", the aspects emphasised differ. The difference between the contents of the HAQ-S and those of the DFI, 
BASFI, and RLDQ becomes obvious in the ICF categories referring to mobility of the upper extremity and self care, which are only applicable to the HAQ-S. A possible explanation for this finding may be that the HAQ was originally designed as a disease specific instrument for patients with rheumatoid arthritis and was modified for ankylosing spondylitis later on by adding five items to the rheumatoid arthritis version. In ankylosing spondylitis, peripheral arthritis leading to disability of the upper extremity and especially impaired hand and arm use is rather unusual compared with rheumatoid arthritis. This may be the reason why fewer ICF categories referring to mobility of the upper extremity are applicable to the other instruments. Presumably for the same reason, aspects of self care at a general level (d5) and especially the specific concept of "washing oneself" (d510) are represented in the HAQ-S, but not in the other selected instruments. This possible explanation is reflected in the fact that none of the five ankylosing spondylitis specific items of the HAQ-S could be linked to the chapter d5 of the ICF (table 4).

Although questionnaires assessing physical functional ability in patients with ankylosing spondylitis, such as the BASFI, the DFI, the HAQ-S, and the RLDQ, can be successfully linked to the ICF, the classification should not be regarded as a substitute for these instruments. In the future, it can serve as a common reference for all outcome measures. Some results of the linking procedure, however, may provide helpful arguments for a future revision process of the ICF-for example, currently the item "Looking over your shoulder without turning your body" of the BASFI and the concept "Are you able to look in the rear view mirror?" as well as "Are you able to turn your head to drive in reverse?" of the HAQ-S had to be assigned to the more general parent category "d498" (mobility, other specified").

As involvement of the cervical spine leading to impaired neck rotation can be regarded as one of the most important limitations in patients with ankylosing spondylitis, ${ }^{9}$ categories exactly representing this concept could be added to one of the next versions of the classification. The latter also holds for the item "How much stiffness have you had because of your illness" of the HAQ-S. Spinal stiffness-one of the major complaints in ankylosing spondylitis-had to be linked to the ICF category 7800 ("sensation of muscle stiffness"), as the current version of the ICF does not include any other category closer to the sense of spinal stiffness.

The ICF based comparison provides information about the contents addressed in the different measures. Therefore, it can be a useful tool when selecting specific measures for a study. The first question when selecting measures is to decide what should be measured in consideration of the study end points, the population studied, and the planned intervention. The second question is to decide which measure to use. If one considers the contents covered in different measures, a selection based on the question "What should be measured?" can be made. Moreover, using the ICF as a reference framework allows a researcher or a recommending body to see which domains are covered in a specific instrument and therefore whether it is necessary to complement the study with further measures. When compared with other types of qualitative review, the most important advantage of the content comparison of measures based on the ICF is the use of an external and independent reference to which all the instruments can be linked and by which all the instruments can be compared.

Measures vary both in the breadth of the dimensions measured and in the thoroughness and depth with which these different dimensions are measured. ${ }^{20}{ }^{21}$ Thus the comparison of instruments often represents a cumbersome exercise. This could explain why many studies compare the psychometric properties of instruments but content comparisons are scarcely represented in the literature. As comparison based on the ICF is carried out at the level of concepts, this difficulty is overcome. Comparison based on the ICF provides insight into both the bandwidth of the different generic instruments - that is, the breadth of health dimensions measured-and the precision of the instruments-that is, the thoroughness and depth of measurement.

\section{Conclusion}

The ICF provides an excellent common framework when comparing the contents of disease specific instruments for patients with ankylosing spondylitis. The linking process is a very valuable tool for making a detailed critical analysis of instruments for assessing physical functional ability, as it clearly shows which health domains are covered by them. For a future revision of the ICF, the specification of major limitations in patients with ankylosing spondylitis could provide a reference framework to define exactly what should be measured and which measures or items should be selected in detail to provide the most comprehensive picture of patients with ankylosing spondylitis. The ICF could then serve as a guideline for the design of innovative disease specific instruments for ankylosing spondylitis.

\section{Authors' affiliations}

T Sigl, G Stucki, Department of Physical Medicine and Rehabilitation, University Hospital Munich, Ludwig-Maximilians-University, Munich, Germany

A Cieza, ICF Research Branch, WHO FIC Collaborating Centre (DIMDI), IHRS, Ludwig-Maximilians-University

D van der Heijde, Department of Rheumatology, University Hospital Maastricht, Maastricht, Netherlands

\section{REFERENCES}

1 Khan MA. Ankylosing spondylitis: clinical features. In: Klippel JH, Dieppe PA, eds. Rheumatology. London: CV Mosby, 1998:6.16.1-9.

2 Khan MA. Update on spondylarthropathies. Ann Intern Med 2002;136:896-907.

3 Arnett FC. Ankylosing spondylitis. In: Koopman WJ, ed. Arthritis and allied conditions. Baltimore: Williams\& Wilkins, 1997:1 197-208.

4 Van der Heijde D, Calin A, Dougados M, Khan MA, van der Linden S, Bellamy N. Selection of instruments in the core set for DC-ART, SMARD, physical therapy, and clinical record keeping in ankylosing spondylitis. Progress report of the ASAS Working Group. J Rheumatol 1999;26:951-4.

5 Van der Heijde D, Bellamy N, Calin A, Dougados M, Khan AM, van der Linden. Preliminary core sets for endpoints in ankylosing spondylitis. J Rheumatol 1997;24:11.

6 Calin A, Garret S, Whitelock H, Kennedy LG, O'Hea J, Mallorie P, et al. A new approach to defining functional ability in ankylosing spondylitis: the development of the Bath Ankylosing Spondylitis Functional Index. J Rheumatol 1994;21:2281-5.

7 Dougados M, Gueguen A, Nakache JP, Nguyen M, Mery C, Amor B. Evaluation of a functional index and an articular index in ankylosing spondylitis. J Rheumatol 1988;15:302-7.

8 Dougados M, Gueguen A, Nakache JP, Nguyen M, Amor B. Evaluation of a functional index in ankylosing spondylitis (letter). I Rheumatol 1990;21:2281-5.

9 Daltroy LH, Larson MG, Roberts WN, Liang M. A modification of the health assessment questionnaire for the spondylarthropathies. I Rheumatol 1990;17:946-50

10 Abbott CA, Helliwell PS, Chamberlain MA. Functional assessment in ankylosing spondylitis: evaluation of a new self-administered questionnaire and correlation with anthropometric variables. Br J Rheumatol 1994;33:1060-6.

11 World Health Organization. Technical report on burden of musculoskeletal diseases. Geneva: WHO, 2002.

12 Ruof J, Stucki G. Comparison of the Dougados Functional Index and the Bath Ankylosing Spondylitis Functional Index. A literature review. J Rheumatol 1999;26:4

13 Eyres S, Tennant A, Kay L, Waxman R, Helliwell PS. Measuring disability in ankylosing spondylitis: comparison of bath ankylosing spondylitis functional index with revised Leeds Disability Questionnaire. J Rheumatol, 2002 May, 29:979-86.

14 Boers M, Brooks P, Strand VC, Tugwell P. The OMERACT filter for outcome measures in rheumatology (editorial). J Rheumatol 1998;25:198-9. 
15 World Health Organisation. International Classification of Functioning, Disability and Health: ICF. Geneva: WHO, 2001.

16 Cieza A, Brockow T, Ewert T, Amann E, Kollerits B, Chatterij S, et al. Linking health-status measurements to the international classification of functioning, disability and health. J Rehabil Med 2002;34:1-6.

17 Cohen J. A coefficient of agreement for nominal scales. Educ Psychol Measure 1960;20:37-46.

18 Vierkant RA. An SAS macro for calculating bootstrapped confidence intervals about a Kappa coefficient. SAS Users Group International Online
Proceedings. Available at: http://www2.sas.com/proceedings/sugi22/ STATS/PAPER295.PDF. Accessed 23 July 2004.

19 Weigl M, Cieza A, Harder M, Geyh S, Amann E, Kostanjsek N, et al. Linking Osteoarthritis specific health status measures to the ICF. Osteoarthritis Cartilage 2003;11:519-23.

20 Kessler RC, Mroczek DK. Measuring the effects of medical interventions. Med Care 1995;33:109-19.

21 McHorney CA. Generic health measurement: past accomplishments and a measurement paradigm for the 21 st century. Ann Intern Med 1997;15:743-50.

\section{Clinical Evidence - Call for contributors}

Clinical Evidence is a regularly updated evidence-based journal available worldwide both as a paper version and on the internet. Clinical Evidence needs to recruit a number of new contributors. Contributors are healthcare professionals or epidemiologists with experience in evidence-based medicine and the ability to write in a concise and structured way.

Areas for which we are currently seeking authors:

- Antenatal monitoring

- Dietary supplementation and treatments in pregnancy

- Palliative care

- Prolonged pregnancy

We are also looking for authors for existing topics. For full details on what these chapters are please visit www.clinicalevidence.com/ceweb/contribute/index.jsp

However, we are always looking for others, so do not let this list discourage you.

Being a contributor involves:

- Selecting from a validated, screened search (performed by in-house Information Specialists) epidemiologically sound studies for inclusion.

- Documenting your decisions about which studies to include on an inclusion and exclusion form, which we keep on file.

- Writing the text to a highly structured template (about 1500-3000 words), using evidence from the final studies chosen, within 8-10 weeks of receiving the literature search.

- Working with Clinical Evidence editors to ensure that the final text meets epidemiological and style standards.

- Updating the text every 6 months using any new, sound evidence that becomes available. The Clinical Evidence in-house team will conduct the searches for contributors; your task is simply to filter out high quality studies and incorporate them in the existing text.

- To expand the topic to include a new question about once every 12-18 months.

If you would like to become a contributor for Clinical Evidence or require more information about what this involves please send your contact details and a copy of your CV, clearly stating the clinical area you are interested in, to CECommissioning@bmigroup.com.

\section{Call for peer reviewers}

Clinical Evidence also needs to recruit a number of new peer reviewers specifically with an interest in the clinical areas stated above, and also others related to general practice. Peer reviewers are healthcare professionals or epidemiologists with experience in evidence-based medicine. As a peer reviewer you would be asked for your views on the clinical relevance, validity, and accessibility of specific topics within the journal, and their usefulness to the intended audience (international generalists and healthcare professionals, possibly with limited statistical knowledge). Topics are usually 1500-3000 words in length and we would ask you to review between 2-5 topics per year. The peer review process takes place throughout the year, and out turnaround time for each review is ideally 10-14 days.

If you are interested in becoming a peer reviewer for Clinical Evidence, please complete the peer review questionnaire at www.clinicalevidence.com/ceweb/contribute/peerreviewer.jsp 